\title{
Estudo das reações alcalis-sílica associadas ao uso da lama vermelha em argamassas colantes e de revestimento
}

\section{(Study of alkali-silica reactions associated with the use of red mud in plastering mortars)}

\author{
D. V. Ribeiro ${ }^{I^{*}}$,A.M.S.Silva ${ }^{2}$, J.A. Labrincha ${ }^{3}$, M.R.Morelli ${ }^{1}$ \\ ${ }^{l}$ Departamento de Engenharia de Materiais, Universidade Federal de S. Carlos, Rod. Washington Luiz, km 235, \\ S. Carlos, SP 13566-550, Brasil \\ ${ }^{2}$ Laboratório Nacional de Engenharia Civil (LNEC), v. do Brasil 101, Lisboa, 1700-066, Portugal \\ ${ }^{3}$ Departamento de Engenharia Cerâmica e do Vidro, Universidade de Aveiro \& CICECO, Campus Universitário \\ de Santiago,Aveiro,3810-193, Portugal \\ verasribeiro@hotmail.com,ssilva@lnec.pt,jal@ua.pt,morelli@ufscar.br
}

\begin{abstract}
Resumo
A incorporação de resíduos industriais em matrizes cimentícias, com o objetivo de inertização, é uma alternativa de reutilização que tem sido bastante estudada nos últimos anos. No presente trabalho, estudou-se a lama vermelha, resíduo sólido gerado no processo de beneficiamento da bauxita e que, devido a seu elevado $\mathrm{pH}$, é considerado "perigoso". Apesar do uso deste resíduo ter sido reportada em trabalhos anteriores, algumas patologias podem estar associadas à sua utilização, devido à elevada concentração de íons alcalinos (principalmente o sódio), favorecendo as reações álcalis-sílica (RAS) e às dificuldades de moldagem (reologia) devido à elevada finura deste resíduo. Apesar destes prováveis problemas provenientes do uso indiscriminado da lama vermelha como adição às argamassas e concretos, ainda são poucas as pesquisas que os contemplam, sendo este o foco do presente trabalho. Foram verificadas as propriedades reológicas das argamassas, utilizando um reômetro e a avaliação da RAS, de acordo com as normas ASTM C 1260-07 e NBR 11582. Os resultados obtidos foram bastante satisfatórios quanto ao comportamento das argamassas frente à RAS, apesar da elevada concentração de álcalis na lama vermelha, com grande influência reológica.

Palavras-chave: cimento, argamassas, lama vermelha, RAS, durabilidade, reologia.
\end{abstract}

\begin{abstract}
The incorporation of industrial wastes in cementitious matrices, with the goal of inertization, is an alternative of reuse that has been extensively studied in recent years. In this paper, the red mud, the main waste generated in aluminum and alumina production by the Bayer process from bauxite ore and considered "hazardous" due to the high $\mathrm{pH}$, was studied. Despite the use of this waste have been reported in previous studies, some pathologies may be associated with its use, due to high concentration of alkali ions (mainly sodium), favoring the alkali-silica reactions (ASR) and the difficulties of molding (rheology) because of high fineness of this waste. Despite these potential problems arising from the indiscriminate use of red mud as an addition to mortars and concrete, there are few studies that contemplate this problem, and is the focus of the present work. The rheological properties of mortars were studied using a rheometer, and the evaluation of ASR was evaluated, according to ASTM C 1260-07 and NBR 11582 standards. The results were very satisfactory as to the mortars behavior concerning the ASR, despite the high alkali concentration in red mud, with great rheological influence.
\end{abstract}

Keywords: cement, mortar, red mud, ASR, durability, rheology.

\section{INTRODUÇÃO}

A produção mundial de bauxita em 2008 foi de cerca de 205 milhões de toneladas, e os principais países produtores foram Austrália, China, Brasil, Guiné, Índia e Jamaica. Ocupando a $3^{\text {a }}$ posição no ranking mundial em 2008, o Brasil produziu 26,6 milhões de toneladas de bauxita, possuindo

"Endereço atual: Departamento de Ciência e Tecnologia dos Materiais, Universidade Federal da Bahia, Rua Aristides Novis 02, Federação, Salvador, BA 41210-630 também a terceira maior reserva de minério de bauxita do mundo (cerca de 3,5 bilhões de toneladas), concentrado principalmente no norte do país (estado do Pará) [1]. Entre 0,31,0 tonelada de lama vermelha são gerados para cada tonelada de alumínio produzido. Cerca de 10,6 milhões de toneladas de lama vermelha cáustica são descartadas anualmente durante os últimos anos no Brasil, enquanto a geração mundial atinge mais de 117 milhões de toneladas/ano [2].

A lama vermelha é um resíduo sólido proveniente da indústria de beneficiamento da bauxita. É um material complexo, cuja composição química e mineralógica varia 
muito, dependendo da fonte de bauxita e dos parâmetros do processo tecnológico de produção. Baseado nos 3 diferentes tipos de produção da alumina, a lama vermelha pode ser classificada como lama vermelha Bayer, lama vermelha sinterizada ou lama vermelha proveniente dos dois métodos combinados. Devido ao fato de mais de $90 \%$ da alumina produzida em todo o mundo ser proveniente do processo Bayer, pesquisas que busquem alternativas a este tipo de resíduo têm particular importância. A estocagem desta grande quantidade de resíduo alcalino (lama vermelha) é cara (entre 1 e $2 \%$ do preço da alumina), requer uma grande área de disposição (cerca de $1 \mathrm{~km}$ quadrado por cinco anos para uma fábrica que produza 1 Mton de alumina por ano) e provoca uma série de problemas ambientais [3]. Assim, a utilização deste resíduo em matrizes cimentícias torna-se bastante atrativa pelo fato da elevada quantidade de cimento consumido em todo o mundo ser compatível com a geração também bastante elevada deste resíduo.

Matrizes alcalinas como as de cimento Portland (argamassas e concretos) são comumente usadas no acondicionamento de resíduos. Elas são baratas, mostram uma história amplamente documentada de segurança, e são provenientes de uma tecnologia facilmente acessível. A alcalinidade reduz a solubilidade de muitas espécies inorgânicas perigosas e inibe processos microbiológicos. Além disso, uma vez que essas matrizes necessitam de água para hidratação, elas podem facilmente incorporar resíduos úmidos [1], tais como a lama vermelha. A lama vermelha foi escolhida para o presente trabalho, devido aos seus elevados teores de alumina e óxidos de ferro. Diversos estudos têm avaliado a utilização da lama vermelha diretamente como um componente do clínquer [3- 6], e a sua adição às formulações de argamassa e concreto também foi relatada [7]. Os cimentos baseados em compostos aluminoferrosos têm uma série de vantagens sobre o cimento Portland comum [6]. Estas incluem a conservação de energia e a redução das emissões de $\mathrm{CO}_{2}$, devido à temperatura mais baixa de clinquerização e formação de clinquers mais leves, capacidade de reutilizar resíduos industriais, características de boa resistência, boas propriedades anti-infiltração, boa resistência à corrosão e pega rápida. A busca por alternativas ambientalmente $\mathrm{e}$ economicamente viáveis de reciclagem incluem aplicações da lama vermelha como adsorvente para a remoção de cádmio, zinco e arsênio, flúor, chumbo e cromo em soluções aquosas [8], como componente de materiais de construção, tais como tijolos [9], cerâmicas e telhas [10], esmaltes [11], como compósitos de base polimérica para substituir a madeira [12], cimentos ricos em ferro [5, 6], etc. A utilização como material de construção comum tem sido sugerida como uma alternativa que garante altas taxas de consumo [13]. No entanto, seu uso indevido pode causar sérias patologias em argamassas de revestimentos ou até mesmo descolamento do revestimento cerâmico devido ao processo expansivo, resultado da reação álcalis-sílica (RAS). A degradação do concreto por ações químicas é um fenômeno extremamente complexo, envolvendo muitos parâmetros, nem sempre fáceis de serem isolados e que atuam em diferentes graus. As reações álcalis-agregado (RAA) são reações químicas que se desenvolvem entre constituintes reativos dos agregados e íons alcalinos e hidroxilos presentes na solução intersticial da pasta de cimento, podendo ter um efeito altamente prejudicial para as argamassas [14, 15]. Estas reações são de caráter fortemente expansivo, levando ao desenvolvimento de tensões internas no material e conseqüente fissuração, freqüentemente acompanhadas do aparecimento de eflorescências e exsudações à superfície. Apesar de dificilmente ser referida como causa primária do colapso, a fissuração gerada pela RAA pode favorecer outros processos de deterioração como a carbonatação, descolamento de revestimentos cerâmicos e a corrosão das armaduras, no caso do concreto armado [15]. Existem três tipos distintos de RAA: reações álcalis-sílica (RAS), reações álcalis-silicato e reações álcalis-carbonato. A RAS é o tipo de reação álcalis-agregado mais comum e que tem recebido maior atenção, correspondendo essencialmente a uma reação química entre certas formas de sílica reativa, possuindo estrutura mais ou menos desordenada e, por isso, instável num meio de elevado $\mathrm{pH}$, e os íons alcalinos $\left(\mathrm{Na}^{+}\right.$ e $\left.\mathrm{K}^{+}\right)$e hidroxilos $\left(\mathrm{OH}^{-}\right)$presentes na solução intersticial da pasta de cimento, produzindo um gel de silicato alcalino [15] Devido à elevada concentração de sódio na lama vermelha, a RAS é fonte de grande preocupação. A velocidade de reação dependerá da concentração dos hidróxidos alcalinos na solução intersticial. Os íons cálcio $\left(\mathrm{Ca}^{2+}\right)$, cuja fonte principal é a portlandita (hidróxido de cálcio) formada pelas reações de hidratação do cimento penetram rapidamente no gel, dando origem a geles de silicatos de cálcio, sódio e potássio. Estes geles são capazes de absorver moléculas de água e expandir, gerando forças expansivas $[15,16]$. As reações álcalis-silicato é um fenômeno mais complexo e tem sido pouco explorado. Supõe-se que o mecanismo de expansão seja semelhante à RAS, sendo, no entanto, mais lenta [15]. Freqüentemente estes dois tipos de reações são englobados num mesmo termo genérico de reações álcalis-sílica (RAS). A reação álcalis-carbonato é explicada por uma desdolomitização, ou seja, uma decomposição do carbonato duplo de cálcio e magnésio (dolomita) por ação da solução intersticial alcalina, a qual origina um enfraquecimento da ligação pasta de cimento-inerte. Não há a formação de geles expansivos e a expansão é atribuída à absorção de íons hidróxilos pelos minerais de argila [15]. Assim, os fatores condicionantes da reação álcalis-agregado associados à velocidade da reação são [17, 18]: temperatura, sendo maior a expansão quanto maior a temperatura; umidade elevada; alcalinidade suficientemente elevada da solução intersticial; existência de inertes reativos com concentrações dentro de uma faixa crítica e; granulometria, sendo maior a força de expansão à medida que diminui a superfície específica do material. A RAA só será perigosa quando coexistirem estas condições [14-16]. Assim sendo, devido à elevada concentração de íons $\mathrm{Na}^{+}$e $\mathrm{OH}^{-}$no resíduo de bauxita, provenientes do uso da soda caustica no processo Bayer, as reações álcalis-agregado são foco de preocupação quanto à utilização deste material de elevado $\mathrm{pH}$ como aditivo ao cimento Portland em concretos e argamassas. Segundo diversos autores, uma concentração 
de $\mathrm{Na}_{2} \mathrm{O}$ superior a $0,6 \%$ [14] ou entre 3 e $5 \mathrm{~kg} / \mathrm{m}^{3}$ [19] é suficiente para uma RAA acentuada. Os álcalis presentes no cimento Portland são expressos na forma de óxido de potássio $\left(\mathrm{K}_{2} \mathrm{O}\right)$ e óxido de sódio $\left(\mathrm{Na}_{2} \mathrm{O}\right)$. A quantidade de álcalis disponíveis no cimento Portland é expressa em equivalente alcalino em $\mathrm{Na}_{2} \mathrm{O}\left(\% \mathrm{Na}_{2} \mathrm{O}+0,658 \% \mathrm{~K}_{2} \mathrm{O}\right)$ por apresentar melhor correlação com a expansão devida à reação álcaliagregado [14, 18]. Para ocorrer a RAA, o agregado deve conter formas de sílica capazes de reagir quimicamente com os íons hidroxila e os álcalis presentes na solução dos poros, tais como: vidro vulcânico, sílica amorfa, sílica microcristalina, tridimita, cristobalita, calcedônia, opala, quartzo e feldspato deformados [18].

\section{MATERIAIS E MÉTODOS}

Cimento Portland: utilizou-se um cimento comercial Portland Itau CP-II 32 Z, Itaú.

Lama vermelha: por apresentar-se na forma pastosa, a lama vermelha, gerada pela Alcoa do Brasil em Poços de Caldas, MG, e utilizada neste trabalho foi seca e posteriormente desaglomerada para que se tivesse à disposição um material pulverulento. $\mathrm{O}$ teor de líquido presente inicialmente no resíduo é de cerca de $40 \%$. Isto significa que o teor de sólidos (apenas 60\%) que foi utilizado neste estudo, na verdade, representa um aproveitamento de cerca de 1,67 vezes mais resíduo (100/60). O ideal, se verificada a efetividade da adição deste resíduo, é aproveitar a própria água constituinte como água de mistura da argamassa. Isto seria parte de uma nova etapa do projeto de pesquisa e desenvolvimento.

Areia: para os ensaios de verificação da reação álcalissílica (RAS) foi utilizada uma areia graduada, segundo a respectiva norma, e de alta reatividade, proveniente do rio Tejo, Portugal, com o objetivo de tornar a análise mais efetiva.

Caracterização das matérias primas: a caracterização dos materiais envolveu análises de difração de raios X (Rigaku Geirgeflex ME 210GF2, radiação Cuk $\alpha, 40$ kV, 100 mA, e velocidade de varredura $4 \% \mathrm{~min}$ ) e fluorescência de raios
X (Philips PW1480), enquanto os parâmetros físicos tais como área superficial específica (estimada por BET, usando um equipamento Micrometrics Gemini 2370 V1.02) e a massa específica (Helium Pycnometer Accupyc 1330 V2.01 Micrometrics) também foram determinados.

Determinação de parâmetros reológicos: argamassas de cimento com adição de lama vermelha foram produzidas de acordo com a norma NP EN 196-1, utilizando um traço de 1,0:3,0:0,6 (cimento + lama:areia:água). As propriedades reológicas foram determinadas em um reômetro Viskomat NT Schleibinger Geräte, com uma velocidade de rotação de 150 rpm durante $45 \mathrm{~min}$. A cada $15 \mathrm{~min}$ a velocidade era reduzida para zero, mantida por $30 \mathrm{~s}$ e então se aumentava novamente até $150 \mathrm{rpm}$. O modelo tradicionalmente usado para determinar os parâmetros reológicos (tensão de escoamento e viscosidade plástica) das argamassas é o modelo de Bingham (equação A).

$$
\tau=\tau_{\mathrm{o}}+\mu_{\mathrm{p}} \gamma
$$

na qual $\tau(\mathrm{Pa})$ é a tensão de cisalhamento, $\tau_{\mathrm{o}}(\mathrm{Pa})$ a tensão de escoamento, $\mu_{\mathrm{p}}(\mathrm{Pa} . \mathrm{s})$ a viscosidade plástica e $\gamma\left(\mathrm{s}^{-1}\right)$ a taxa de cisalhamento. Para reômetros que medem o torque T como função da velocidade $\mathrm{N}$, a equação de Bingham pode ser descrita da seguinte forma:

$$
\mathrm{T}=\mathrm{g}+\mathrm{hN}
$$

na qual $\mathrm{T}$ é o torque, $\mathrm{g}$ a tensão de escoamento e $\mathrm{h}$ a viscosidade plástica.

A cada 15 min a velocidade de rotação $\mathrm{N}$ é reduzida para zero. Nesse momento obtém-se a Fig. 1a. Na curva de descida, que está destacada em vermelho, é aplicado o modelo de Bingham, de acordo com a Fig. 1b. A tensão de escoamento g é representada pelo coeficiente linear, enquanto a viscosidade plástica h pelo coeficiente angular.

Reação Álcalis-Sílica (RAS): ainda não existe um método universalmente aceito para a avaliação da reatividade dos

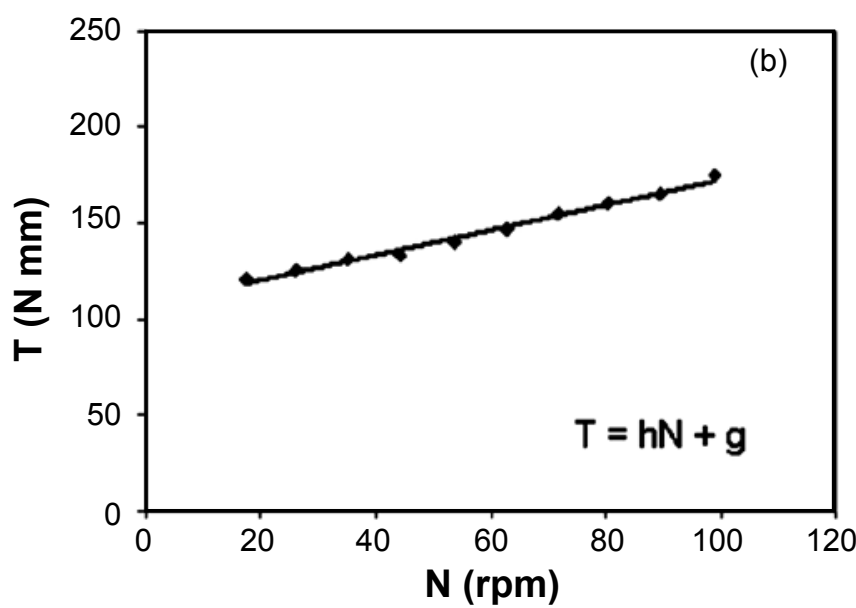

Figura 1: Modelo de Bingham, utilizado na determinação dos parâmetros reológicos (tensão de escoamento, g e viscosidade plástica, h) das argamassas.

[Figure 1: Bingham model used to determine the rheological parameters: yield stress ( $g$ ) and plastic viscosity (h) of mortars.] 
agregados aos inertes [15]. Os dois métodos clássicos desenvolvidos nos Estados Unidos, as normas ASTM C 289 ("Standard test method for potencial alkali reactivity of aggregates - Chemical method") e ASTM C 227 ("Standard test method for potencial alkali reactivity of aggregates Mortar-bar method") estão entre as mais utilizadas. No Brasil o método mais comum para se avaliar a expansibilidade de um aglomerante é a norma NBR 11582 ("Cimento Portland Determinação da expansibilidade de Le Chatelier”). O método químico, embora rápido, não é indicado para todos os tipos de inertes, principalmente os que contêm carbonatos, e não permite uma estimativa do potencial de expansão associado à reatividade do inerte [15]. $\mathrm{O}$ método da barra de argamassa baseia-se na medida das expansões de barras de argamassas conservadas a $38{ }^{\circ} \mathrm{C}$ em ambiente úmido, sendo considerado internacionalmente mais seguro. No entanto, os resultados são obtidos apenas após seis meses de análise e, por isso, foram propostas algumas alterações para acelerar sua obtenção, conservando as amostras de argamassa em soluções alcalinas e aumentando a temperatura de ensaio. É o caso dos métodos de expansão acelerados, que utilizam uma solução de cloreto de sódio a $50{ }^{\circ} \mathrm{C}$ e dos métodos de expansão ultra-acelerados, como o ensaio sul-africano NBRI ("National Building Research Institute") em que o ensaio é realizado a $80^{\circ} \mathrm{C} \mathrm{e}$ conservação em solução de hidróxido de sódio $(\mathrm{NaOH})$.

A norma ASTM C 1260-07 é baseada no método sulafricano e foi utilizada no presente estudo. Segundo esta norma, deve ser usada uma areia graduada e a argamassa deve ter o traço 1,00:2,25:0,47 (aglomerante:areia graduada:água). O aglomerante é composto apenas pelo cimento na amostra de referência ( $0 \%)$, que é substituído pela lama vermelha nos teores de $10 \%, 20 \%$ e $30 \%$ para as respectivas composições. Após a mistura das matérias-primas, são moldados três corpos de prova prismáticos $\left(25 \times 25 \times 285 \mathrm{~mm}^{3}\right)$ para cada composição $(0 \%, 10 \%, 20 \%$ e $30 \%)$. Estes corpos de prova devem ser desmoldados $24 \mathrm{~h}$ após a moldagem e terem o seu comprimento aferido. A seguir, colocam-se os corpos de prova em recipiente com água, em estufa a $80 \pm 2{ }^{\circ} \mathrm{C}$, onde as amostras devem permanecer por mais $24 \mathrm{~h}$ até nova medida do comprimento. Após esta medida, deve-se colocar os corpos de prova em solução de $\mathrm{NaOH}(1 \mathrm{~N})$ também em estufa a $80 \pm 2{ }^{\circ} \mathrm{C}$ e realizam-se medidas do comprimento a cada dois dias, até completarem-se 16 dias de ensaio (14 dias em $\mathrm{NaOH})$. A expansão é calculada como o aumento percentual do comprimento ao longo do ensaio, sendo considerado para análise que: expansões inferiores a $0,10 \%$ aos 16 dias são indicativas de comportamento inócuo, isto é, a expansão é desprezível; expansões de mais de $0,20 \%$ aos 16 dias são indicativas de expansão potencialmente deletéria; expansões entre $0,10 \%$ e $0,20 \%$ aos 16 dias são duvidosas. Para estes casos, é interessante continuar o ensaio até os 28 dias, com o objetivo de verificar se o limite de expansão igual 0,20\% é ultrapassado.

Para a avaliação da expansibilidade via agulhas de Le Chatelier (NBR 11582), prepara-se uma pasta com consistência normal, segundo a MB 3433 ("Determinação da água de consistência normal"), preenchendo-se o cilindro (30 $\mathrm{mm}$ de diâmetro e $30 \mathrm{~mm}$ de altura) de oito agulhas e deixando em cura imersa por $24 \mathrm{~h}$. Após as $24 \mathrm{~h}$ iniciais, medem-se os afastamentos das extremidades das hastes e colocam-se, a seguir, quatro agulhas em cura a frio durante sete dias e as outras quatro em cura a quente, em água fervendo, até que não se verifiquem em duas medições consecutivas, variações de afastamento das extremidades das hastes. A expansibilidade a frio visa verificar a influência do $\mathrm{MgO}$ e a expansibilidade a quente visa verificar a influência do $\mathrm{CaO}$. Os resultados apresentados são uma média dos valores observados.

\section{RESULTADOS E DISCUSSÃO}

\section{Caracterização das matérias-primas}

Cimento Portland e areia: o cimento Portland utilizado tem área superficial específica $0,93 \mathrm{~m}^{2} / \mathrm{g}$ e massa específica

Tabela I - Composição química do cimento Portland, obtida pela técnica de espectrometria de fluorescência de raios $\mathrm{X}$ (em óxidos).

[Table I - Chemical composition of Portland cement estimated by XRF (oxides).]

\begin{tabular}{llllllllll}
\hline Composto & $\mathrm{CaO}$ & $\mathrm{SiO}_{2}$ & $\mathrm{Al}_{2} \mathrm{O}_{3}$ & $\mathrm{MgO}$ & $\mathrm{Fe}_{2} \mathrm{O}_{3}$ & $\mathrm{SO}_{3}$ & $\mathrm{Na}_{2} \mathrm{O}$ & $\mathrm{K}_{2} \mathrm{O}$ & $\mathrm{PF}$ \\
\hline Teor $(\%)$ & 56,00 & 24,50 & 6,10 & 4,00 & 2,50 & 1,80 & 0,45 & 0,25 & 4,10 \\
\hline
\end{tabular}

Tabela II - Composição química da lama vermelha, obtida pela técnica de espectrometria de fluorescência de raios X (em óxidos). [Table II - Chemical composition of red mud estimated by XRF (oxides).]

\begin{tabular}{ccccccccccc}
\hline Composto & $\mathrm{Al}_{2} \mathrm{O}_{3}$ & $\mathrm{Fe}_{2} \mathrm{O}_{3}$ & $\mathrm{Na}_{2} \mathrm{O}$ & $\mathrm{CaO}$ & $\mathrm{SiO}_{2}$ & $\mathrm{~K}_{2} \mathrm{O}$ & $\mathrm{MnO}$ & $\mathrm{TiO}_{2}$ & Outros & $\mathrm{PF}$ \\
\hline Teor (\%) & 19,87 & 19,87 & 7,35 & 4,61 & 14,34 & 1,87 & 0,21 & 2,66 & 2,02 & 27,20 \\
\hline \multicolumn{8}{c}{ Após correção da perda ao fogo (PF) } \\
\hline Teor (\%) & 27,30 & 27,30 & 10,10 & 6,33 & 19,70 & 2,57 & 0,29 & 3,65 & 2,76 & - \\
\hline
\end{tabular}


Tabela III - Resultados de caracterização física e de pH da lama vermelha seca e desaglomerada.

[Table III - Physical characterization and $\mathrm{pH}$ results of dried red mud.]

\begin{tabular}{cc}
\hline Grandeza & Resíduo de Bauxita \\
\hline Área superficial específica & $20,27 \mathrm{~m}^{2} / \mathrm{g}$ \\
Massa unitária & $0,63 \mathrm{~kg} / \mathrm{dm}^{3}$ \\
Massa específica & $2,90 \mathrm{~kg} / \mathrm{dm}^{3}$ \\
pH $(1: 1)$ & 12,04 \\
\hline
\end{tabular}

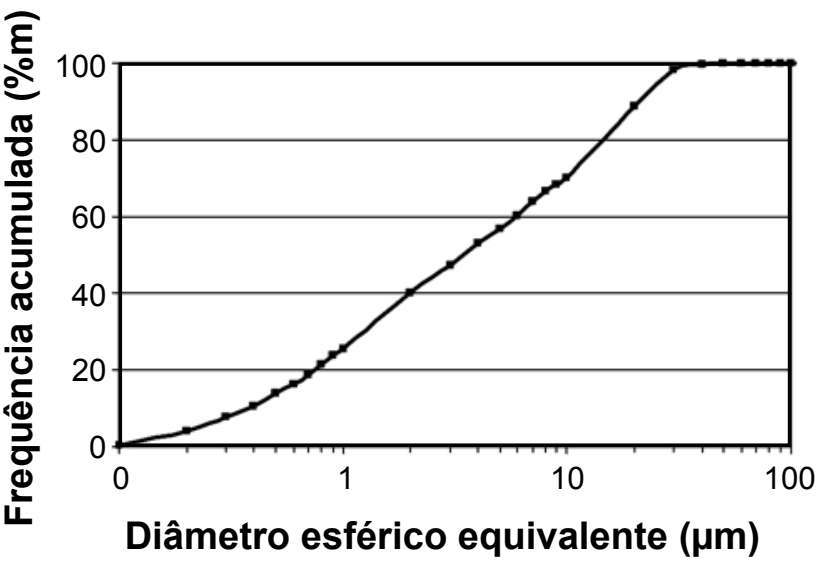

Figura 2: Distribuição do tamanho de partículas da lama vermelha seca e desaglomerada (resultado médio de cinco determinações). [Figure 2: Particle size distribution of the dried red mud.]
$3,11 \mathrm{~kg} / \mathrm{dm}^{3}$. A composição química do cimento é apresentada na Tabela I. A areia apresentou área superficial específica $0,68 \mathrm{~m}^{2} / \mathrm{g}$ e massa específica $2,70 \mathrm{~kg} / \mathrm{dm}^{3}$. De acordo com a norma brasileira NBR 7211 esta areia é classificada como "areia fina".

Lama vermelha: a lama vermelha foi recebida como uma pasta, contendo cerca de $40 \%$ de água livre. O material foi seco e moído e então utilizado em pó. A composição química da lama vermelha é apresentada na Tabela II e as principais características físicas na Tabela III. A alta concentração de compostos ferrosos dá ao resíduo da bauxita uma cor vermelha típica.

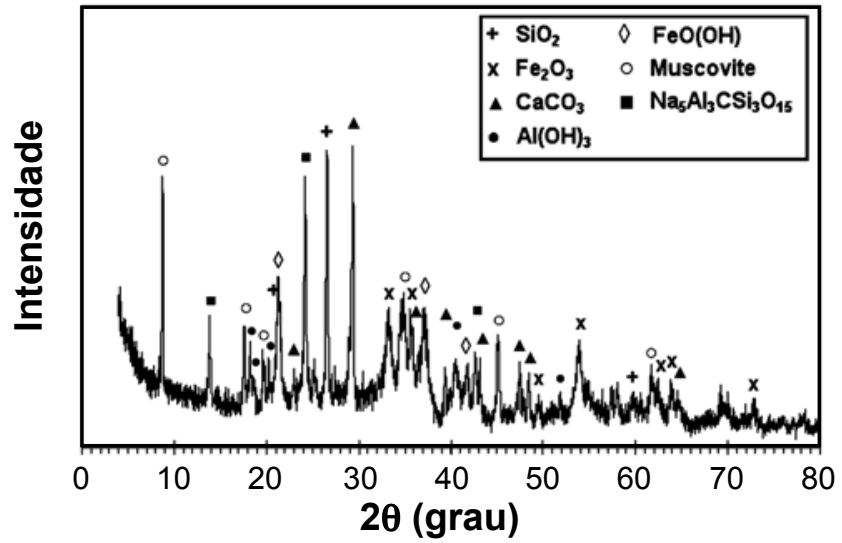

Figura 3: Difratograma de raios $\mathrm{X}$ da lama vermelha. [Figure 3: X-ray diffraction pattern of the red mud.]
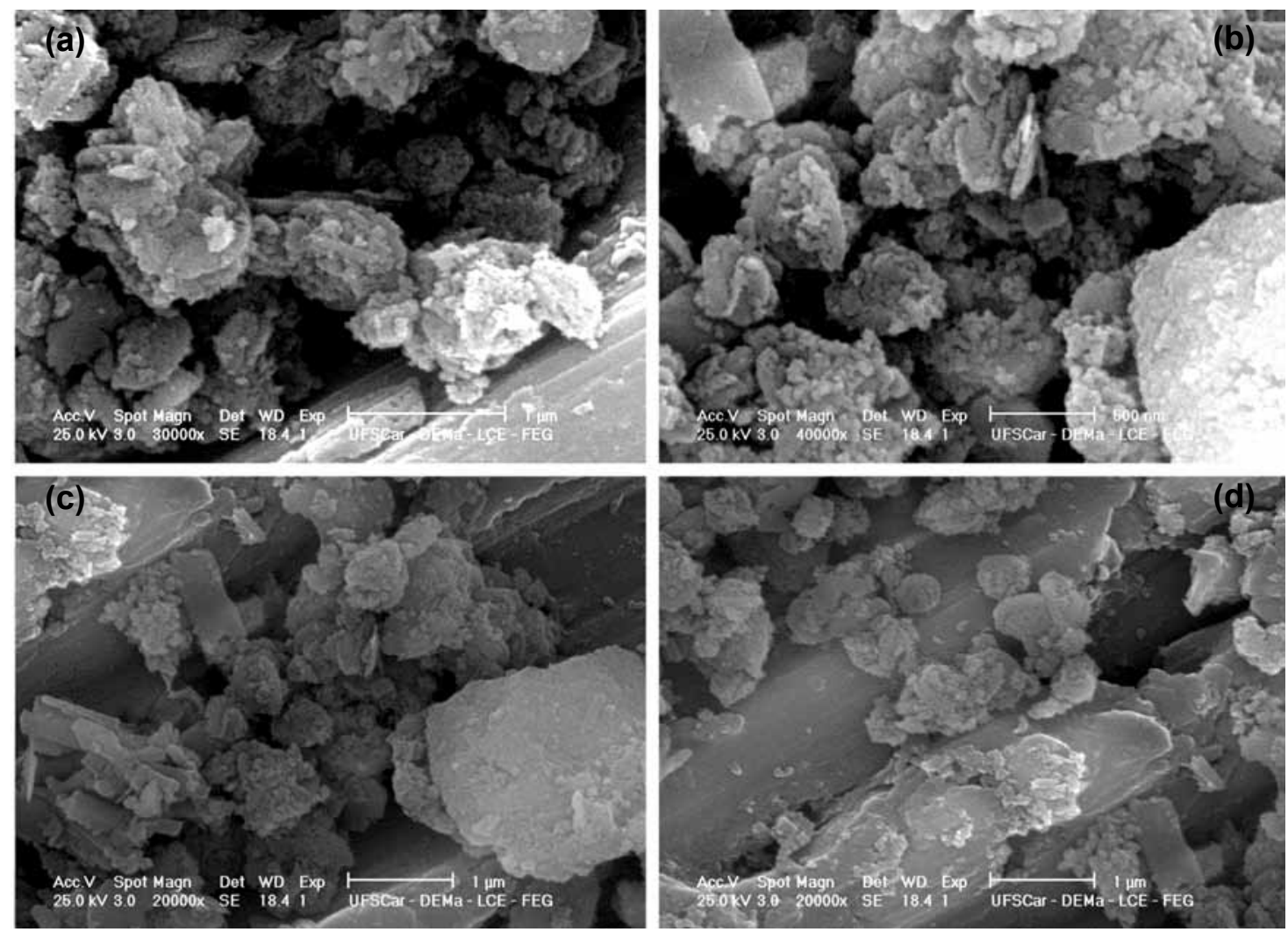

Figura 4: Micrografias obtidas por microscopia eletrônica de varredura da lama vermelha seca e desaglomerada. [Figure 4: SEM micrographs of dried and crushed red mud.] 
Uma característica que chama a atenção é a área superficial do resíduo de bauxita, bastante elevada, o que mostra ser este resíduo muito mais fino que o próprio cimento Portland e o elevado $\mathrm{pH}$, próximo ao limite da norma NBR 10004. Verificou-se ainda a distribuição do tamanho de partículas e as fases presentes no resíduo. Estes resultados podem ser verificados na Fig. 2 e pelo difratograma de raios $\mathrm{X}$ da Fig. 3.

O diâmetro médio de partículas $\left(\mathrm{D}_{50}\right)$ da lama vermelha é igual a 3,5 $\mu \mathrm{m}$. Como esperado, o hidróxido de alumínio $\left(\mathrm{Al}(\mathrm{OH})_{3}\right)$, o carbonato de cálcio $\left(\mathrm{CaCO}_{3}\right), \mathrm{o} \mathrm{SiO}_{2}$ e o óxido de ferro $\left(\mathrm{Fe}_{2} \mathrm{O}_{3}\right)$ são os compostos predominantes. No entanto, quantidades relativas de muscovita e $\mathrm{FeO}(\mathrm{OH})$ são também relevantes. Além destes, uma fase complexa de sódio e alumínio, o carbonato silicato de sódio e alumínio $\left(\mathrm{Na}_{5} \mathrm{Al}_{3} \mathrm{CSi}_{3} \mathrm{O}_{15}\right)$ foi identificada. Com o objetivo de verificar a forma das partículas da lama vermelha após desaglomeração, utilizou-se um microscópio eletrônico de varredura. As micrografias são mostradas na Fig. 4. $\mathrm{O}$ resíduo de bauxita apresenta uma estrutura floculada, associada a placas. É uma estrutura que favorece a adição às matrizes cerâmicas por ser semelhante à encontrada no cimento Portland.

\section{Determinação de parâmetros reológicos}

Devido ao fato da lama vermelha ser extremamente fina e eventualmente apresentar propriedades pozolânicas, sua presença em misturas cimentícias as torna menos fluídas e dificultam a moldagem dos corpos de prova (em laboratório) ou o espalhamento uniforme da pasta (argamassa de revestimento). Com o objetivo de se observar esta influência, utilizou-se o modelo de Bingham, determinando-se a tensão de escoamento $g$ e a viscosidade plástica h das misturas (Fig. 5).

Como pode ser observado na Fig. 5, não foi possível efetuar a medição para a argamassa com adição de $30 \%$ de lama vermelha, pois estas ficaram muito rígidas, acima da capacidade de torque do aparelho (reômetro) utilizado. De

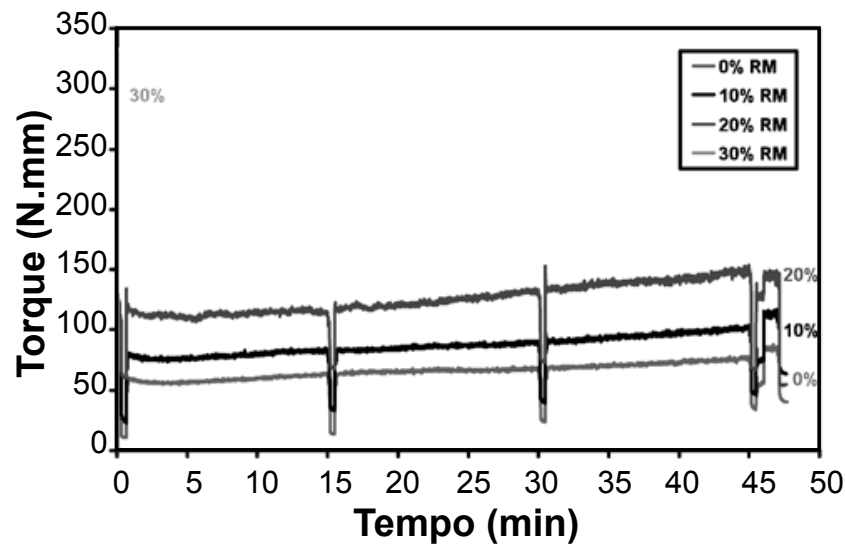

Figura 5: Reologia das argamassas de cimento Portland contendo lama vermelha como adição, expressa em função do torque medido utilizando-se o reômetro.

[Figure 5: Torque values of red mud containing mortars.]

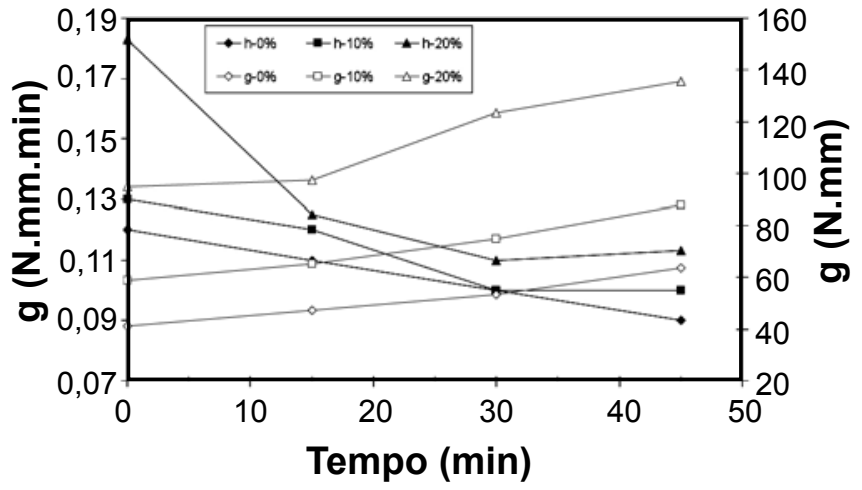

Figura 6: Valores de viscosidade plástica (h) e da tensão de escoamento $(\mathrm{g})$ das argamassas contendo diversos teores de lama vermelha, obtidos a partir do Modelo de Bingham.

[Figure 6: Values of plastic viscosity $(h)$ and yield stress $(g)$ of red mud containing mortars, obtained by Bingham's Model.]

uma forma geral, como esperado, há um aumento da tensão de escoamento (g) e uma diminuição da viscosidade plástica (h) com o passar do tempo, devido à hidratação do cimento e à menor quantidade de água livre na mistura, como pode ser visto na Fig. 6. Este comportamento é mais evidente à medida que se adiciona maior quantidade da lama vermelha, podendo ser reflexo de uma atividade cimentícia da lama vermelha ou simplesmente um efeito físico da presença de um material mais fino e que "seqüestra" a água da mistura. Acredita-se que, nos instantes iniciais, o fator físico é mais preponderante, tornando menos importante com o passar do tempo, quando a hidratação do cimento se torna mais efetiva. Este comportamento está de acordo com o obtido por Tsakirids et al. [5], que observaram um aumento da consistência nas misturas que continham lama vermelha.

\section{Reação álcalis-sílica}

Uma grande preocupação quando se pensa em utilizar a lama vermelha como adição em matrizes cimentícias é o fato de este resíduo apresentar um elevado teor de álcalis, principalmente o sódio. Como mostrado na revisão de literatura, a reação álcalis-sílica é altamente prejudicial à estrutura do concreto. A reação entre os hidróxidos alcalinos solubilizados na fase líquida dos poros dos concretos e alguns agregados reativos é lenta e resulta em um gel que, ao se acumular em vazios da matriz e na interface pasta-agregado, na presença de água, se expande, exercendo pressão interna no material. Ao exceder a resistência à tração, a pressão interna pode promover fissurações. A reação álcali-agregado requer a atuação conjunta de água, agregado reativo e álcalis [18].Assim, foram realizados testes para avaliar uma possível reação álcalis-agregado. Escolheu-se o método das barras e o das agulhas de Le Chatelier por serem os mais aceitos internacionalmente. Para que os resultados provenientes do método das barras fossem realçados, utilizou-se uma areia de elevada reatividade. Assim, as amostras de referência ( $0 \%$, sem resíduo) apresentaram uma expansão média igual a $0,30 \%$ já aos 14 dias, chegando a $0,47 \%$ aos 28 dias. Esta expansão da amostra de referência já é bastante acima do 
valor considerado "seguro" $(0,10 \%)$ ou "duvidoso" $(0,20 \%)$. A adição da lama vermelha surpreendentemente reduziu a expansibilidade destas argamassas, provocada pela RAA. Para uma adição de $30 \%$, inclusive, a expansão aos 28

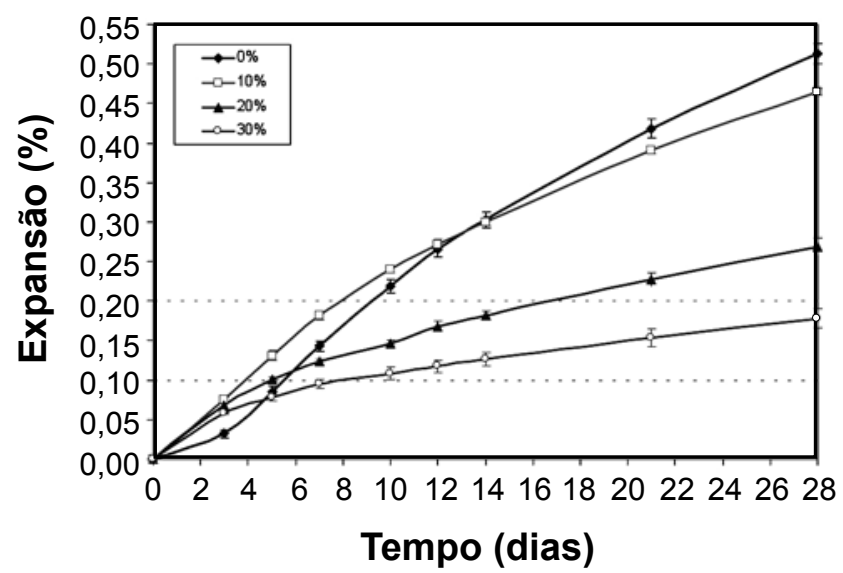

Figura 7: Curvas de expansão das argamassas contendo lama vermelha como adição, para a verificação da reação alcalis-sílica, de acordo com a norma ASTM C 1260-07.

[Figure 7: Expansion of red mud containing mortars to verify the alkali-silica reaction, according to ASTM C 1260-07.] dias ficou abaixo dos 0,20\%. Observa-se na Fig. 7 que nos instantes iniciais (primeiros cinco dias), a expansão dos corpos de prova contendo lama vermelha foi mais acentuada do que as amostras de referência. Aparentemente o $\mathrm{Na}^{+}$livre presente na lama vermelha foi consumido nestes primeiros instantes, na reação com o agregado reativo, favorecendo uma menor expansão nos momentos seguintes.

Alguns autores já demonstraram que entre as alternativas para reduzir a reação álcalis-sílica está a adição de materiais pozolânicos ativos $[18,20]$. Assim a reatividade da lama com o cimento pode ter sido mais relevante positivamente do que a elevada presença de álcalis, que contribui negativamente. Possivelmente, o fato de a lama vermelha ser rica em sódio é pouco relevante neste ensaio, já que a solução de contato $(\mathrm{NaOH} 1 \mathrm{~N})$ fornece sódio em quantidade mais que suficiente para a RAS. Assim, as amostras têm expansão superior ao limite dos $0,10 \%$ aos 14 dias, pois a quantidade de álcalis do material pode ser mobilizada para o ataque de sílica reativa nas primeiras $48 \mathrm{~h}$ antes da argamassa ser imersa na soda. Esta expansão pouco pronunciada é também observada por meio de microscopia ótica. Como pode ser observado na Fig. 8, não se verificam grandes diferenças entre as espessuras dos geles formados entre a pasta e o
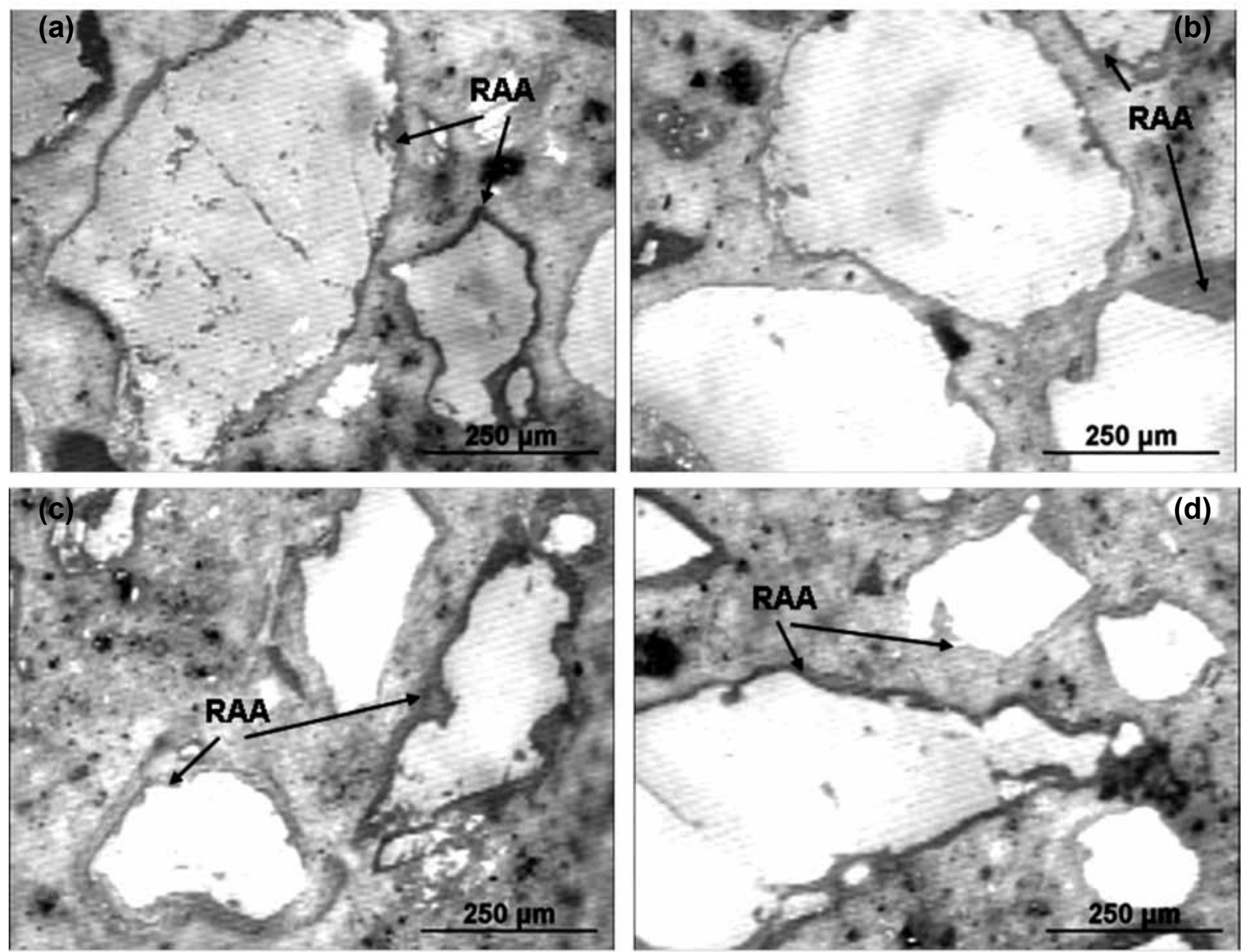

Figura 8: Micrografias ópticas de amostras das argamassas de cimento Portland: (A) e (B) sem a presença de resíduo (0\%) e; (C) e (D) contendo $20 \%$ de resíduo como adição.

[Figure 8: Optical micrographs of Portland cement mortars samples: $(A)$ and $(B)$ without the waste presence $(0 \%)$, and $(C)$ and (D) containing $20 \%$ waste as addition.] 
agregado nas Figs. 8A e 8B (sem resíduo) e as observadas nas Figs. 8C e 8D (contendo 20\% de resíduo).

A diminuição da expansão com adição sucessiva da lama vermelha pode ter ocorrido devido a um efeito de diluição do teor de cimento, pois o cálcio é fundamental no mecanismo da RAS [21, 22]. A minimização da expansão, relacionada à redução do teor de hidróxido de cálcio na argamassa, que diminuiu com o aumento do teor de adições pozolânicas ativas no cimento, foi verificada em extensivo estudo [18]. Resultados semelhantes aos apresentados na Fig. 8 haviam sido obtidos [31] que, ao se adicionar cinzas volantes (material pozolânico) ao concreto, foi observada uma expansão menor em comparação às amostras de referência. Coincidentemente, estudos [18] mostram que o teor mínimo de adição de pozolana ativa para que a reação álcali-agregado seja mitigada é entre $10 \%$ e $15 \%$. No presente estudo foi observado que este valor é de cerca de $20 \%$.

Além do método das barras, buscou-se avaliar as possíveis reações expansivas, resultantes da utilização da lama vermelha, por meio do método de expansibilidade de Le Chatelier. Os resultados obtidos são apresentados na Fig. 9.

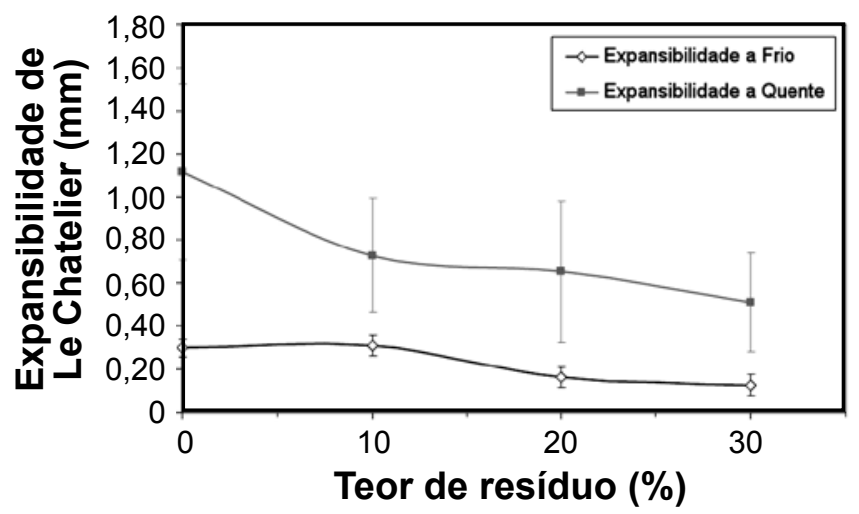

Figura 9: Expansibilidade de pastas de cimento Portland contendo diversos teores de lama vermelha, obtidos por meio das agulhas de Le Chatelier, de acordo com a norma NBR 11582.

[Figure 9: Expansibility of red mud containing Portland cement pastes, obtained by Le Chatelier needles, according to NBR 11582 standard.]

A expansibilidade a frio tem como objetivo verificar a influência do $\mathrm{MgO}$ e a expansibilidade a quente visa verificar a influência do $\mathrm{CaO}$. Assim, ao contrário do esperado para o método das barras, a substituição do cimento Portland pela lama vermelha tende a reduzir a expansibilidade de Le Chatelier, uma vez que os teores de $\mathrm{MgO}$ (não detectado) e $\mathrm{CaO}(4,6 \%)$ neste resíduo são razoavelmente inferiores aos encontrados no cimento Portland (4\% e 56\%, respectivamente), como foi mostrado nas Tabelas I e II. Esta expectativa foi confirmada pelos resultados obtidos, que mostram uma evidente redução da expansibilidade para as duas condições de ensaio. Como esperado, a expansibilidade a frio é muito baixa, uma vez que tanto a lama vermelha quanto o cimento apresentam baixos teores de $\mathrm{MgO}$ e a expansibilidade a quente apresenta uma queda acentuada de
$1,12 \%$ (referência) para $0,51 \%$ (30\% de lama vermelha), o que reflete a diferença considerável nos teores de $\mathrm{CaO}$ entre o cimento Portland e o resíduo (56,0\% contra 4,6\%). Assim, podemos observar que as reações expansivas dos álcalis presentes na lama vermelha $\left(\mathrm{Na}^{+} \mathrm{e} \mathrm{Ca}^{+}\right)$não comprometem o uso deste resíduo em substituição parcial do cimento Portland para aplicações secundárias.

\section{CONCLUSÕES}

A adição da lama vermelha provoca uma diminuição da tensão de escoamento e um aumento da viscosidade plástica das argamassas, devido à hidratação do cimento e à menor quantidade de água livre na mistura (elevada finura do material); a avaliação da carbonatação em corpos de prova de concreto apenas torna-se viável e reprodutível com a utilização de câmara de carbonatação, devido ao lento processo que leva a este fenômeno; contrariamente ao esperado, a lama vermelha não aumenta a reação álcalissílica (RAS). Este fenômeno pode estar associado a um efeito de diluição do teor de cimento, pois o cálcio é fundamental no mecanismo da RAS; a presença da lama vermelha proporciona uma redução na expansibilidade proveniente da reação com o $\mathrm{MgO}$ e o $\mathrm{CaO}$ para as duas condições de ensaio (a frio e a quente); as reações expansivas dos álcalis presentes na lama vermelha $\left(\mathrm{Na}^{+} \mathrm{e} \mathrm{Ca}\right)$ não comprometem o uso deste resíduo em substituição parcial do cimento Portland para aplicações secundárias.

\section{AGRADECIMENTOS}

Ao $\mathrm{CNPq}$, ao PPGCEM/UFSCar, à Universidade de Aveiro/Departamento de Cerâmica e Vidro - Projeto FCTPTDC/CTM/65243/2006.

\section{REFERÊNCIAS}

[1] IBRAM - Brazilian Mining Association. Bauxita, Disponível em <http://www.ibram.org.br/sites/1300/1382/ 00000033.pdf>, acesso em 15/05/2010.

[2] ROSKILL REPORTS, The Economics of Bauxite \& Alumina, disponível em <http://www.roskill.co.uk/index. html>, acesso em 20/07/2010.

[3] M. Singh, S. N. Upadhayay, P. M. Prasad, Waste Management 16, 8 (1996) 665.

[4] F. P. Glasser, J. Hazardous Mater. 52, 2-3 (1997) 151.

[5] P. E. Tsakiridis, S. Agatzini-Leonardou, P. Oustadakis, J. Hazardous Mater. 116, 1-2 (2004) 103.

[6] M. Singh, S. N. Upadhayay, P. M. Prasad, Cem. Concr. Res. 27, 7 (1997) 1037.

[7] M. Cabeza, A. Collazo, X. R. Nóvoa, M. C. Pérez, J. Corrosion Sci. Eng. 6, 32 (2003) 1.

[8] S. S. Amritphale, A. Anshul, N. Chandra, N. Ramakrishnan, J. Eur. Ceram. Soc. 27, 4 (2007) 1945.

[9] S. S. Amritphale, M. Patel, Silicates Ind. 2, 3 (1987) 31.

[10] M. S. Vincenzo, C. Renz, M. Stefano, C. Giovanni, J. 
Eur. Ceram. Soc. 20, 3 (2000) 245.

[11] N. Yalcin, V. Sevnic, Ceram. Int. 26, 5 (2000) 485.

[12] P. Asokan, M. Saxean, S. R. Asolekar, Resources Conservation Recycling 43, 3 (2005) 239.

[13] J. N. Gordon, W. R. Pinnock, M. M. Moore, Cem. Concr. Composites 18, 6 (1996) 371.

[14] P. K. Mehta, P. J. M. Monteiro, Concreto: estrutura, propriedades e materiais, Ed. PINI, S. Paulo, Brasil (1994) p. 249.

[15] M. O. B. Reis, A. M. S. Silva, Reacções álcalis-sílica: recomendações gerais para prevenir a deterioração do betão, Lisboa: Laboratório Nacional de Engenharia Civil (Boletim Técnico. ITCM 23) (1997) 27 p.

[16] P. E. Sichieri, J. M. Pablos, O. P. Ferreira, J. A. Rossignolo, R. Caram, Materiais de construção 1, Ed. USP, S. Carlos (2008) p. 271.
[17] F. R. Andriolo, Observação de estruturas de concreto: Validade quanto à ocorrência da reação alkali-agregado, Anais do Simpósio sobre Reatividade Álcali-Agregado em Estruturas de Concreto, Goiânia, GO (1997) p. 14.

[18] F. A. C. Munhoz, Efeito de adições ativas na mitigação das reações álcali-sílica e álcali-silicato, Diss. Mestrado em Construção Civil, Escola Politécnica, Universidade de S. Paulo, S. Paulo (2008) 166 p.

[19] P. Rivard, M. A. Bérubé, J. P. Ollivier, G. Ballivy, Mater. Structures 40, 9 (2007) 909.

[20] I. García-Lodeiro, A. Palomo, A. Fernández-Jiménez, Cem. Concr. Res. 37, 2 (2007) 175.

[21] R. F. Bleszynskisnd, M. D. A. Thomas, Adv. Cem. Based Mater. 7, 2 (1998) 766.

[22] M. H. Shehata, M. D. A. Thomas, Cem. Concr. Res. 30, 7 (2000) 1063 .

(Rec. 19/08/2010, Rev.06/03/2011, Ac. 25/03/2011) 